\section{Treatment of Tuberculous Empyema by Intrathoracic Transposition of a Latissimus Dorsi Muscle Flap}

Byeong Jun $\mathrm{Kim}^{1}$, In Pyo Hong ${ }^{1}$, Chan Min Chung ${ }^{1}$, Woo Sik Kim ${ }^{2}$

Departments of ${ }^{1}$ Plastic and Reconstructive Surgery and ${ }^{2}$ Thoracic Surgery, National Medical Center, Seoul, Korea

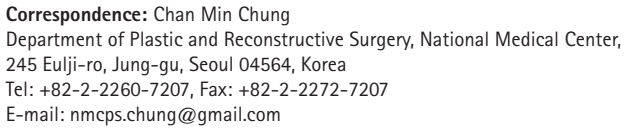

No potential conflict of interest relevant to this article was reported.

Received: 4 May $2015 \bullet$ Revised: 26 Oct $2015 \bullet$ Accepted: 4 Nov 2015 pISSN: 2234-6163 - elSSN: 2234-6171 http://dx.doi.org/10.5999/aps.2016.43.1.117 Arch Plast Surg 2016;43:117-119

Copyright (C) 2016 The Korean Society of Plastic and Reconstructive Surgeons This is an Open Access article distributed under the terms of the Creative Common Attribution Non-Commercial License (http://creativecommons.org/licenses/by-nc/3.0/) which permits unrestricted non-commercial use, distribution, and reproduction in any medium, provided the original work is properly cited.

South Korea has the highest prevalence of tuberculosis among the Organization for Economic Cooperation and Development nations [1], despite the management of pulmonary tuberculosis with antituberculosis drugs. Therefore, South Korea also has a relatively high prevalence of tuberculous

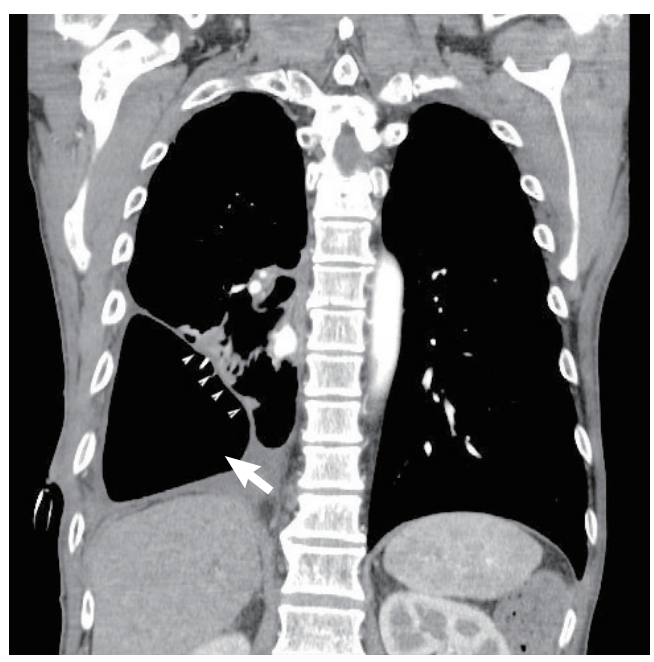

Fig. 1.

A chest computed tomography scan shows a large dead space (white arrow) in the right thoracic area that resulted from the right lower lobectomy, as well as enhancing rims of the parietal and visceral pleurae (white arrowheads) surrounding a loculated pleural fluid collection (split pleura sign). empyema, a complication of tuberculosis that accounts for 3\%-6\% of all cases of empyema [2]. A chronic, active infection of the pleural space, tuberculous empyema is a refractory disease requiring long-term medication and drainage [3]. We report our success in transposing the latissimus dorsi (LD) muscle into the pleural space in order to prevent the recurrence of tuberculous empyema.

In 2012, a 53-year-old male patient diagnosed with pulmonary tuberculosis recovered completely after receiving treatment. However, he experienced recurrence of pulmonary tuberculosis in 2014, and during treatment, a computed tomography (CT) image revealed that the right lower lobe of his lung had collapsed. This led to the occurrence of tuberculous empyema, and the patient was hospitalized to undergo thoracic surgery to treat the empyema. The patient's condition did not improve during the operation, despite the continuous administration of medication and chest tube drainage. The thoracic surgeon therefore performed a lung lobectomy with decortication, and we decided to transpose the $\mathrm{LD}$ muscle flap into the resulting cavity (Fig. 1).

We first identified the pleural space on the chest CT image and calculated the approximate volume of the space $\left(203 \mathrm{~cm}^{3}\right)$. The flow of the thoracodorsal artery was determined using a pencil Doppler and the latissimus border was outlined with a marker. After determining the amount of LD muscle required, we determined the necessary incision length and drew the incision lines (Fig. 2). The incision started in the

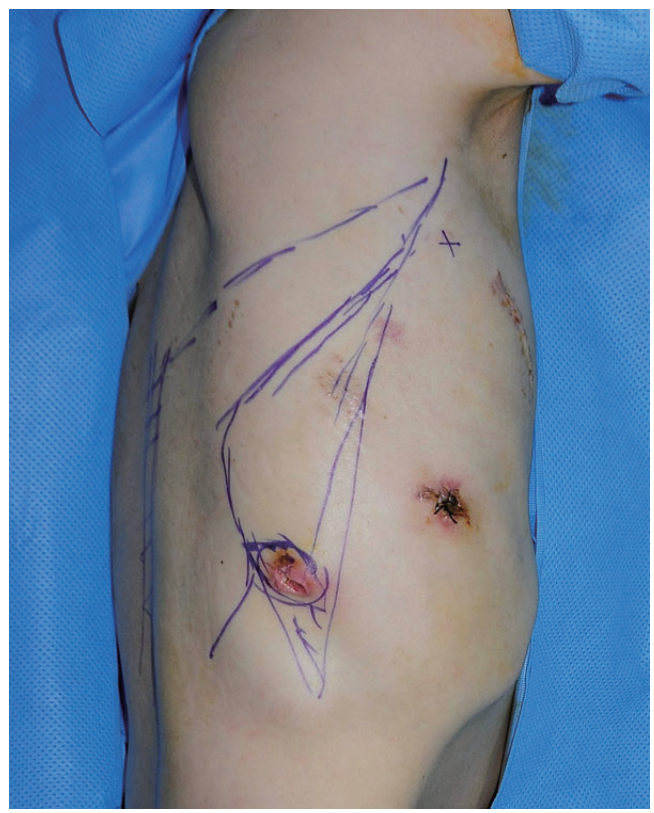

Fig. 2.

Preoperative skin diagram. The lines depict surface projections of the latissimus dorsi (LD) muscle. The axillary incision design for harvest of the LD is shown in relation to the anterior border of the muscle. 
Fig. 3.

The separated latissimus dorsi muscle flap.

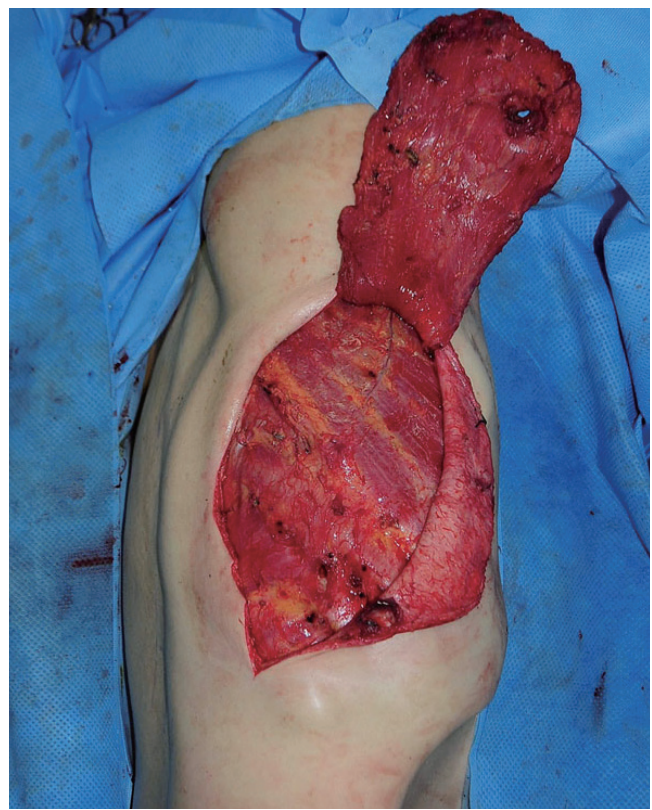

posterior axillary fold and continued inferiorly and medially to expose the LD muscle. The skin and fat flaps were elevated to the extent necessary to produce a pocket allowing the adequate harvest of muscle tissue. We then identified the anterior border of the exposed LD muscle and its superior border below the inferior angle of the scapula.

While performing a ligation of the perforators below the LD muscle from the superior border, the muscle was elevated to the midline. Once the medial portion of the muscle was reached, dissection was carried out inferiorly using electrocautery, and the desired amount of LD muscle was separated (Fig. 3).

Next, we determined the viability of the separated LD muscle flap. In order to perform a LD muscle flap transposition into the pleural space, the serratus anterior muscle was split, the fifth rib was exposed, a portion was excised, and a second window was created in the pleural space. The LD muscle flap was then carefully inserted into the pleural space through this second window to prevent the vascular pedicle from being twisted or pulled (Fig. 4).

Using 2-0 Vicryl sutures, the muscle was loosely tacked to the mediastinal pleura. After undermining the subcutaneous layer on both sides of the incision, the muscle donor site was closed primarily without tension, and a chest tube was placed for pleural drainage. In addition, two Jackson-Pratt drains were placed at the muscle donor site in order to prevent seroma formation. Both the tube and drains were removed four weeks after the operation. The wound healed uneventfully. Following surgery, however, the

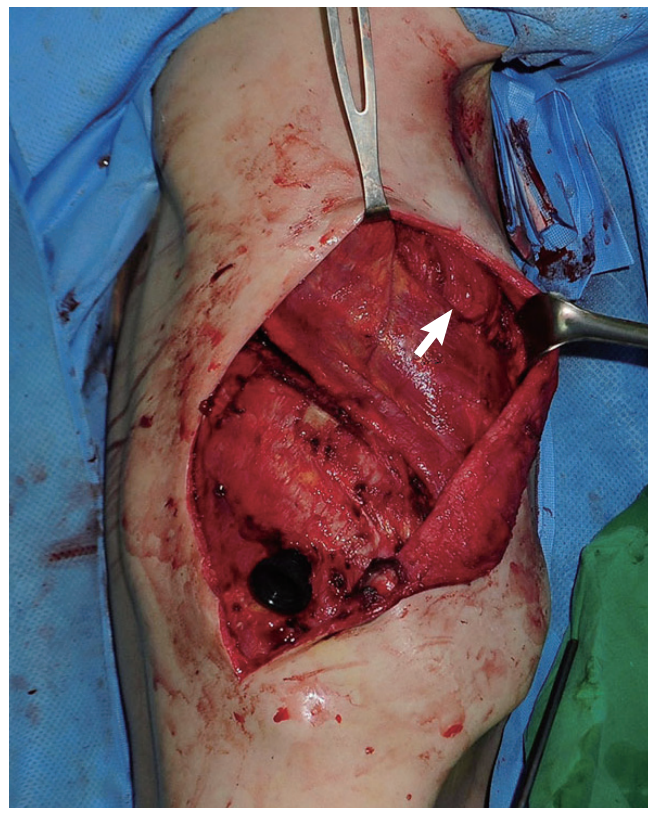

Fig. 4.

The latissimus dorsi muscle flap was inserted into the pleural space through a second window created by splitting the serratus anterior muscle (white arrow).

patient was treated with antibiotics for four weeks after the occurrence of pneumonia in the right lung (Fig. 5). At a later follow-up, the patient displayed no signs of functional disability or chest wall contour deformity related to the LD harvest. At a twelvemonth follow-up examination, he was in good condition with no recurrence of empyema.

Sufficient drainage, infection control, and optimal nutrition play a crucial role in the treatment of empyema [4]. However, if these strategies do not succeed in curing the empyema, surgery must be considered. In particular, when lung lobectomy is performed, a large cavity occurs, which may lead to potentially life-threatening empyema or secondary infection.

The LD muscle flap was used simply to fill the dead space, but with the goal of producing well vascularized tissue resistant to chronic infection and disposed to angiogenesis and healing. The LD muscle has a blood supply with a type $V$ pattern. Most of the supply comes through a thoracodorsal artery pedicle, along with lesser flows through perforators from the thoracic intercostal and lumbar arteries. Since the LD muscle is able to produce the largest extrathoracic muscle flap that can be harvested as a single vascular pedicle (up to $20 \mathrm{~cm} \times 40 \mathrm{~cm}$ ), it is utilized by many plastic and reconstructive surgeons.

Although the LD muscle enables extension, 


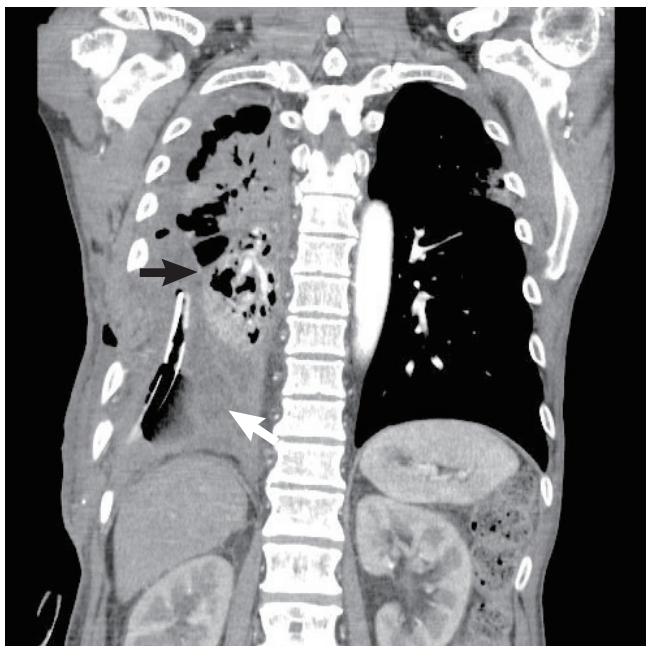

Fig. 5.

Two weeks postoperatively, a chest computed tomography scan shows the pleural space filled by the intrathoracic transposition of the latissimus dorsi muscle flap (white arrow). A chest computed tomography scan of the right upper lobe shows pneumonia (black arrow).

adduction, and internal rotation of the shoulder joint, it does not function independently. Since it moves in synchrony with a number of synergistic shoulder girdle muscles, the LD muscle can be sacrificed safely without affecting shoulder or arm action [5].

A major surgical advantage of using the LD muscle flap in the field of thoracic surgery is the fact that, because it is an extrathoracic muscle, ipsilateral lung surgery can be performed while simultaneously obtaining the LD muscle through a single posterolateral thoracotomy incision. Furthermore, due to its large bulk and long vascular pedicle, the LD muscle flap can move in apical or mid-thoracic dead space easily with minimal tension, obliterating the pleural space.

However, because a LD flap based on the thoracodorsal artery can be short, alternative flaps (e.g., a rectus abdominis flap) should be considered for movement to the lower, supra-diaphragmatic recess of the pleural space. Various flaps can also be used depending on the location of the dead space, such as a serratus anterior flap for the upper region of the thorax and a pectoralis flap or a trapezius flap for the apical region.

Tuberculous empyema is uncommon and, unlike other types of empyema, difficult to treat. We performed a lobectomy and used the intrathoracic transposition of a LD muscle flap into the resulting cavity to treat a tuberculous empyema patient who had not improved from the administration of antituberculosis drugs and chest tube drainage. This operation was relatively easy and the patient had no recurrence of empyema or other complications.

\section{References}

1. World Health Organization. Global tuberculosis report 2015 [Internet]. Geneva, Switzerland: World Health Organization; c2015 [cited 2015 Dec 29]. Available from: http://www.who.int/tb/publications/global_ report/en/.

2. Jess P, Brynitz S, Friis Moller A. Mortality in thoracic empyema. Scand J Thorac Cardiovasc Surg 1984;18:85-7.

3. Iseman MD, Madsen LA. Chronic tuberculous empyema with bronchopleural fistula resulting in treatment failure and progressive drug resistance. Chest 1991;100:124-7.

4. Meyer AJ, Krueger T, Lepori D, et al. Closure of large intrathoracic airway defects using extrathoracic muscle flaps. Ann Thorac Surg 2004;77:397-404.

5. Abolhoda A, Bui TD, Milliken JC, et al. Pedicled latissimus dorsi muscle flap: routine use in high-risk thoracic surgery. Tex Heart Inst J 2009;36:298-302.

\section{Non-Invasive Imaging of Preoperative Mapping of Superficial Veins in Free Flap Breast Reconstruction}

Michael W Chu ${ }^{1}$, Jonathon R Sarik ${ }^{2}$, Liza C Wu ${ }^{3}$, Joseph M Serletti ${ }^{3}$, Jonathan Bank ${ }^{4}$

${ }^{1}$ Division of Plastic and Reconstructive Surgery, Indiana University, Indianapolis, IN; ${ }^{2}$ Department of Surgery, Thomas Jefferson University, Philadelphia, PA; ${ }^{3}$ Division of Plastic and Reconstructive Surgery, University of Pennsylvania, Philadelphia, $P A ;{ }^{4}$ New York Breast Reconstruction Associates, Great Neck, NY, USA

Correspondence: Michael W Chu

Division of Plastic and Reconstructive Surgery, Indiana University, 545 Barnhill Drive \#232, Indianapolis, IN 46202, USA

Tel: +1-215-662-7300, Fax: +1-215-662-2172

E-mail:dr.michael.chu@gmail.com

No potential conflict of interest relevant to this article was reported.

Received: 20 Jul 2015 • Revised: 21 Sep 2015 • Accepted: 24 Sep 2015 pISSN: 2234-6163 • elSSN: 2234-6171

http://dx.doi.org/10.5999/aps.2016.43.1.119

Arch Plast Surg 2016;43:119-121

Copyright (C) 2016 The Korean Society of Plastic and Reconstructive Surgeons This is an Open Access article distributed under the terms of the Creative Commons Attribution Non-Commercial License (http://creativecommons.org/licenses/by-nc/3.0/) which permits unrestricted non-commercial use, distribution, and reproduction in any medium, provided the original work is properly cited.

Vascular anatomy is imperative in reconstructive surgery to ensure perfusion and accurate flap design, 